\title{
GUEDES, Simoni Lahud; CIPINIUK, Tatiana Arnaud (Org.). 2014. Abordagens etnográficas sobre educação: adentrando os muros das escolas. Niterói: Editora Alternativa. 219pp.
}

\author{
MARCOS ALFONSO SPIESS
}

Com a ampliação das políticas públicas educacionais que ocorreu nas últimas décadas - tais como as políticas de cotas, da educação do campo e da educação indígena - cresceu o número de pesquisas antropológicas sobre os e nos contextos escolares. Com base na diversidade que começou a ser vista nas instituições de ensino, por vezes a antropologia é demandada a acompanhar a elaboração, a implementação e mesmo os resultados dessas políticas educacionais voltadas a grupos sociais minoritários e historicamente excluídos da educação formal.

Ao mesmo tempo que antropólogos se aproximaram das escolas, local ainda considerado o lugar por excelência da atividade educacional, também os educadores se apropriaram de técnicas de pesquisa da antropologia, especialmente da etnografia, com o objetivo de melhor compreender a pluralidade do campo no qual atuam. Produzido a partir dessa relação entre educadores e antropólogos, a obra Abordagens etnográficas sobre Educação apresenta diferentes pesquisas etnográficas realizadas em ambientes educacionais, além de aprofundar questões teóricas dessa relação interdisciplinar.

O livro, lançado em 2014 sob a coordenação de Simoni Guedes e Tatiana Cipiniuk, é resultado do Seminário sobre Educação e Antropologia, realizado em 2012, na Universidade Federal Fluminense. Além de diferentes perspectivas teóricas e metodológicas, uma multiplicidade de temas perpassa a discussão, dentre os quais: o ensino religioso, a educação de jovens e adultos, educação e classe social, gestão escolar, juventude e o papel social da escola. Essa diversidade temática, organizada em três seções distintas, traz na primeira parte uma discussão de cunho teórico e metodológico desenvolvida pelas pesquisadoras Neusa Gusmão e Tânia Dauster.

$\mathrm{Na}$ segunda parte da obra, estão agrupados quatro trabalhos sobre "Escolas e ensino público", sendo dois sobre aspectos da organização institucional e dois sobre sociabilidade escolar. Por fim, na última seção, também com quatro trabalhos, discute-se modalidades de ensino, especificamente sobre o ensino religioso em escolas públicas, a Educação de Jovens e Adultos e os impactos do Programa Universidade para Todos (Prouni).

Sobre o porquê do intenso diálogo entre a educação e a antropologia, Gusmão afirma que a primeira razão aponta a "antropologia como necessária, em razão de seu escopo humanitário e de seus mé- 
todos no campo da pesquisa, nomeadamente as pesquisas etnográficas" (:14). O segundo motivo diz respeito ao conceito de cultura e seu alcance explicativo em relação à diversidade cultural e às diferenças identitárias cada vez mais latentes nos contextos escolares. Essas razões fazem com que a antropologia se apresente como possibilidade de compreensão da perspectiva de igualdade e de homogeneização produzida pelo Estado e pela educação formal, mas que na prática se configura em múltiplas realidades e diferenças sociais. Para Gusmão, relativizar a igualdade e fazer emergir a diferença configura a "sensibilidade especial do antropólogo e da antropologia para compreender as propriedades da vida social” (:16).

Essas “propriedades da vida social", para Dauster, conferem à antropologia o papel de "compreender a unidade biológica da espécie humana e a sua diversidade cultural" (:27). Pautando-se na teoria interpretativa de C. Geertz, a professora Dauster vê a antropologia como possibilidade de distanciamento e estranhamento daquilo que muitas vezes está naturalizado. À antropologia caberia a tarefa de interpretar os significados, os sistemas simbólicos e as classificações que subjazem os diferentes contextos sociais, inclusive os escolares. Para Dauster, a relação entre antropologia e educação se dá a partir de seus próprios objetos de estudos: os modos de vida, os valores e, principalmente, as diferentes formas de socialização. Ressalta-se que, de acordo com a autora, a relação entre essas duas áreas de conhecimento se constitui a partir de um saber de fronteira, ou seja, um saber híbrido e sempre envolto a tensões acadêmicas, teóricas e institucionais.

No primeiro trabalho de cunho etnográfico, que abre a seção sobre Escolas e ensino público, Delma Neves problematiza qual o papel da escola na sociedade brasileira e a questão do descrédito do ensino público. Sua etnografia, realizada em duas escolas públicas no Rio de Janeiro, buscou mapear os discursos sobre o papel do ensino público desde os atores que integravam os ambientes escolares, notadamente os professores. A pesquisa tornou possível identificar a polarização de dois projetos de ação escolar "defendidos ou assumidos por novos e antigos professores" (:41), os quais estão fundamentados, respectivamente, no argumento de que à escola caberia a instrução e, contrariamente, na concepção de que à escola deveria se comprometer com a educação. Enquanto os professores mais novos eram acusados de se preocuparem apenas com a instrução, com a reprodução conteudística e de informações, de outro lado, os docentes mais velhos se identificavam com um projeto holístico de escola pública, o qual deveria promover a educação das crianças e dos jovens com base em valores morais e sociais.

Para compreender a disputa por qual deveria ser o modelo de escola, Neves resgata a história do ensino público brasileiro apontando que, se até décadas passadas o magistério constituía uma das classes profissionais mais politizadas e a docência era revestida por uma áurea devocional, nos últimos anos, a expansão da rede de ensino privado - voltado à educação das elites sociais - fez com que o imaginário acerca das escolas públicas fosse considerado precário e para alunos sem condições sociais. Além disso, as sucessivas perdas salarias e, principalmente, a perda de autoridade dos professores para outros órgãos estatais, como a Polícia e o Conselho Tutelar, prejudicaram o status social atribuído aos professores e, por decorrência, o da escola. A pesquisadora argumenta que essa imagem dos professores, vistos "como agentes desprovidos de referências e possibilidades práticas de requalificação da inserção social de jovens" (:63) intensifica o descrédito da escola pública que ou se vê limitada a reprodução de 
conteúdo e de informações ou, então, torna-se dependente de instituições filantrópicas e OnG’s a fim de atender as demandas sociais das crianças e jovens, especialmente os que estão em situação de rua.

Neves dialoga diretamente com o segundo capítulo etnográfico, que apresenta o trabalho realizado por Yvonne Maggie e Ana Prado, as quais, investigando diferentes formas de organização e gestão escolar, buscam compreender como se constroem as representações sociais das instituições de ensino. A pesquisa se deu através de um trabalho comparativo realizado em trinta e duas escolas públicas de diferentes regiões do Rio de Janeiro, as quais figuram em diferentes posições no ranking classificatório das melhores e piores escolas. O objetivo das pesquisadoras era compreender por que escolas localizadas geograficamente e socialmente próximas serem caracterizadas como opostas.

Para tanto, fundamentando-se nos discursos (re)produzidos por gestores e professores, as autoras propuseram tipos ideais possíveis de gestão escolar: de um lado, a gestão burocrático-racional e, de outro, o tipo carismático. No tipo burocrático-racional, a gestão escolar estaria comprometida em manter a qualidade do ensino a fim de se obter sucesso nas demandas externas que visam a aferir o nível de ensino por meio de exames nacionais e internacionais. Diversamente, a gestão carismática se pautaria na crença de que a boa escola é feita de bons alunos e que a qualidade do ensino depende mais dos alunos do que da instituição.

De acordo com as autoras, "a qualidade de uma escola se constrói dentro dela por meio das ações das pessoas e da eficácia simbólica de suas crenças sobre a educação, a escola e o ensino" (:74). A partir dessas representações geradas dentro das próprias escolas, mediadas pelos diferentes tipos de gestão que são adotados, torna-se possível atribuir diferentes características a essas instituições públicas. Essa tipologia proposta pelas autoras tornou possível explicar a disparidade nas representações sociais das escolas, bem como os motivos de umas serem consideradas melhores que outras.

Ainda considerando o contexto de escolas públicas, o trabalho de Nalayne Mendonça Pinto, desenvolvido em duas escolas públicas do Município de Seropédica (RJ), e que contou com a participação de 20 alunos bolsistas Pibid (Programa Institucional de Bolsa de Iniciação à Docência) do curso de Ciências Sociais da UFRRJ, teve por objetivo "apresentar as falas dos alunos [...] sobre suas percepções de formas de conflitos e violências que estão presentes no espaço escolar" (: 83). Com base em vinte e cinco entrevistas, cinco grupos focais e duzentos e cinquenta questionários, a pesquisa demonstrou que os conflitos são constituintes das realidades dos alunos. Os "casos de zoação" são práticas cotidianas que visam a ressaltar as diferenças - geralmente fundamentadas em preconceitos relacionados à religião, ao corpo, à cor, à moradia. No entanto, ao mesmo tempo em que o conflito gera ênfase nas diferenças, são essas mesmas diferenças que criam as "identidades de grupos”, ou seja, as diferenças são ressignificadas por meio da afirmação na sociabilidade vivenciadas em grupos menores.

Com questões próximas às de Mendonça Pinto, o trabalho de José Resende e Luís Gouveia retoma a discussão sobre os conflitos e violências nos espaços escolares. A análise produzida pelos autores, de cunho teórico e fundamentada na Sociologia Pragmática, é resultado de uma pesquisa realizada entre os anos de 2004-2007, em duas escolas populares no norte de Portugal, e um segundo trabalho de campo, realizado entre 2009-2012 junto a quatro escolas na região metropolitana de Lisboa. Refletindo sobre a fabricação dos espaços comuns nas escolas, Resende e Gouveia convidam a pensar como 
que determinados ambientes e tempos escolares são de livre acesso e menos regulados, o que as vezes facilita a ocorrência de violência entre os alunos. $\mathrm{O}$ recreio configura o espaço e o tempo efetivamente comum a todos, em que normas e regras escolares ganham novos contornos e a sociabilidade também é "recriada" pelos sujeitos.

A construção da vida no espaço comum dos ambientes escolares teria como princípio de organização social o regime da philia. É por meio das políticas de amizade, da philia, que são vivenciadas práticas morais, como o reconhecimento e o respeito pelo outro. Por outro lado, a falta de respeito se traduz nos casos de "zoação", de "gozação pública”. Diante dos conflitos gerados pela quebra do regime da philia, a pesquisa evidencia que a inação institucional apenas intensifica o sentimento de injustiça daquele que está sendo "zoado" e reifica o descrédito quanto ao papel formativo holístico das escolas.

Tanto a pesquisa de Mendonça Pinto quanto o trabalho de Resende e Gouveia refletem sobre a afirmação das diferenças (etárias, étnicas, de gênero etc.) no contexto educacional, sua relação com os conflitos entre os estudantes, bem como o papel de prevenção e/ou intervenção da escola nesses conflitos. Os dados etnográficos desses autores confirmam a reflexão teórica desenvolvida por Gusmão e Dauster no início da obra: se, por um lado, as escolas apresentam uma proposta educacional homogeneizante, por outro lado, o cotidiano escolar revela a diversidade marcada pelas diferenças entre os sujeitos que ali convivem. Neste viés, os questionamentos sobre o papel da escola frente os conflitos pautados nessas diferenças reafirmam a necessidade do diálogo entre a antropologia e a educação.

Em outra perspectiva, os quatro trabalhos que constituem a seção "Abordagens etnográficas de modalidades escolares" buscam problematizar diferentes políticas educacionais. Tanto a pesquisa de Ana Paula Miranda, desenvolvida em Portugal, quanto a etnografia de Bóris Maia, realizada no Rio de Janeiro, possuem como objetivo comum compreender o sentido e a prática do ensino religioso em escolas públicas, problematizando a possibilidade de se equacionar o direito à manifestação religiosa e a laicidade do Estado.

A pesquisa de Miranda, marcada por uma robusta análise de documentos institucionais e de legislações, evidencia as relações entre o Estado português e a Igreja Católica demonstrada pela manutenção da disciplina de Religião e Moral Católica nos currículos escolares das escolas públicas. Curiosamente, o trabalho apresenta como o status dessa disciplina foi colocado em xeque não por um grupo a favor da laicização do Estado, mas sim pelas igrejas evangélicas que se expandiram a partir da década de 1980.

A autora demonstra como o argumento de um Estado Laico e de uma sociedade democrática passou a ser (re)apropriado e ressignificado pelas igrejas evangélicas que afirmavam que se a escola deve ser compreendida como um espaço laico e plural, o Estado deveria garantir o respeito e o direito de as crianças evangélicas receberem o ensino sobre seu ethos religioso. A laicidade não poderia, assim, reprimir a expressão religiosa, mas deveria fazê-la emergir no espaço público como expressão cultural.

Essa tese, além de manter a disciplina Religião e Moral Católica, fez incluir no currículo a disciplina de Ensino da Religião e Moral Evangélica. A introdução e a ampliação do ensino religioso em escolas públicas demonstram que, entre o princípio de laicidade e as garantias constitucionais de liberdade de consciência, de religião e de culto, as igrejas conseguiram fundamentar nessas últimas o direito 
de oferta de ensino religioso. Essa interpretação de laicidade dada pelas igrejas representaria o que Miranda denominou de laicidade positiva, ou seja, apesar de laico, haveria a possibilidade de atividades religiosas em instituições públicas a fim de se garantir a diversidade cultural. A laicidade não afastou a religião do Estado, ao contrário, possibilitou que novas religiões (pautando-se no argumento de pluralidade e diversidade cultural), adentrassem as escolas e os espaços públicos.

Sobre o mesmo tema, Bóris Maia desenvolve uma etnografia das aulas de ensino religioso em uma escola pública no Rio de Janeiro. Marcadas pela resistência moral dos alunos, as aulas de ensino religioso configuram um caráter ambíguo dentro da escola. Apesar de ser disciplina obrigatória, os alunos sabem que ela não tem a capacidade de reprovar. Isso faria com que o ensino religioso fosse encarado, pelos alunos, como "matéria de caderno".

O interesse em copiar a matéria estaria vinculado à possibilidade de "ganhar uma moral" com os professores da disciplina e, eventualmente, conseguir notas em outras disciplinas. Não se trata do interesse pela disciplina em si, mas pela função que ela pode assumir em outro contexto como o caso do conselho de classe. Além disso, a pesquisa demonstra como o clima de evitação entre alunos e professores de ensino religioso perpassa o cotidiano da sala de aula, principalmente pela dimensão moralista que a disciplina assume.

Investigando outra modalidade de ensino, a Educação de Jovens e Adultos, Tatiana Cipiniuk aborda a educação como condição de inserção social. Com base em uma etnografia junto a adultos em fase de alfabetização em uma escola pública de Copacabana (RJ), a pesquisadora demonstra que além das dificuldades de se inserirem na sociedade, principalmente no mundo do trabalho, os alunos adultos do ensino básico destacam o sentimento de vergonha, que é produzido pela classificação do analfabeto como um sujeito atrasado, um problema social e anômalo em relação à sociedade.

A pesquisa também revela uma relação ambígua entre ensino e trabalho: ao mesmo tempo em que os alunos enfatizam o ensino como possibilidade de melhorar as condições de vida e de galgarem um emprego com melhores condições humanas e financeiras, é justamente o trabalho um dos fatores que dificultaram a educação formal no tempo legalmente previsto. Se antes a opção pelo trabalho foi a causa do abandono dos estudos. Agora, é o trabalho a causa do retorno à sala de aula, pois ele passa a exigir um nível maior de formação, de educação formal e conhecimento especializado.

Por fim, mantendo as questões que perpassam a relação entre educação, trabalho e classe social, Andréa Mongim aborda o impacto das políticas afirmativas no campo da educação, especificamente o Programa Universidade para Todos (Prouni). A autora ressalta a necessidade de analisar esse programa desde a perspectiva dos próprios alunos beneficiados, motivo pelo qual a pesquisa trata de uma análise dos percursos sociais dos estudantes que rumam ao ensino superior, via Prouni, em uma faculdade particular na capital do Espírito Santo.

Utilizando de "relatos de vida", a autora analisa os mediadores, os diferentes sujeitos que constituem a rede de sociabilidade dos estudantes na execução do projeto de acesso a uma graduação. Se por um lado, o contexto familiar aparece como fundamental na definição da "longevidade escolar", Mongin demonstra que há uma socialização secundária mediada por indivíduos geralmente localizados em quadros institucionais, principalmente professores e colegas de profissão. 
Muitos estudantes ao terminarem o ensino básico são forçados a ingressarem no mercado de trabalho em detrimento da continuidade dos estudos. Porém, as exigências do estudo reaparecem após a entrada no mercado de trabalho. O Prouni, nesse contexto, surge como uma oportunidade para aqueles que se deparavam com a impossibilidade de uma graduação ou que a viam como algo restrito a uma elite social. As pesquisas de Cipiniuk e de Mongin trazem à tona questões sobre educação e condições sociais, e demonstram a aposta que muitos sujeitos fazem na educação como condição de ascensão social.

Os diversos trabalhos que compõem Abordagens etnográficas sobre educação, possibilitam um debate denso acerca do uso da etnografia em contextos escolares. Cada capítulo traz uma síntese de pesquisas, dados consistentes e análises profundas de diferentes contextos de ensino. Apesar de cada capítulo tratar de um tema específico, é possível reconhecer conexões e questões que perpassam toda a obra: o papel da escola, a dimensão da sociabilidade, o sentido da educação formal, educação e condição social são algumas das questões exploradas praticamente por todos os autores.

Além disso, a publicação dessa obra demonstra que, apesar das dificuldades institucionais para se estabelecer o campo da antropologia da educação no Brasil, a relação interdisciplinar entre antropologia e educação está se consolidando. Os trabalhos que compõem a obra demonstram que esse diálogo não é unidirecional, vez que ao mesmo tempo que a antropologia se apropria de contextos educacionais como campo de pesquisa, também os educadores instrumentalizam a antropologia a fim de aprimorar a prática educacional.

Uma limitação da obra, mas que pode significar um convite a novas pesquisas, refere-se ao fato de ele abordar majoritariamente a educação formal básica, permanecendo o desafio de se pensar a educação formal superior. Outra limitação se refere ao fato de, excetuando as duas pesquisas de Portugal, as etnografias dizem respeito a escolas públicas localizadas em regiões urbanas, no sudeste brasileiro, notadamente no Rio de Janeiro. A abordagem sobre a educação é feita por pesquisadores e em locais bem específicos, deixando em aberto a questão de como seria o diálogo entre antropologia e educação desenvolvido em outras regióes do país e em outros contextos sociais que surgem, por exemplo, nas escolas privadas, com educação de pessoas com deficiência, com a educação quilombola, indígena e camponesa.

\section{Marcos Alfonso Spiess é mestre e doutorando em Antropologia pela Universida- de Federal do Paraná (UFPR)}

